\title{
La Filosofia del Derecho de Miguel Reale*.
}

\author{
Luiz Legaz y Lacambra \\ (Da Universidade de Madri).
}

Indubablemente, la orientación de la filosofia del Derecho se endereza tanto contra la consideración tripartita de su temática, que desintegra el conocimiento jurídico en saberes distintos que recaen sobre objetos realmente diferentes (el Derecho como norma, como valor, como hecho social), como contra la concepción unitaria fundada en una "pureza del método", que no hace otra cosa que consagrar de modo más radical esa desintegración de saberes, pero eliminando del ámbito jurídico tanto el aspecto del valor como el de la realidad social, porque el Derecho es "sólo norma" $\mathrm{y}$, en cuanto tal, susceptible de una consideración "puramente jurídica". Ya hace algunos años que Recaséns Siches había señalado que la filosofia del Derecho aspira a un conocimiento primario de lo juridico, que se funde a si mismo plenamente y que sirva de fundamento a las ciencias particulares del Derecho, concepción que responde a una aplicación del punto de vista filosófico al mundo de lo jurídico: toma el mundo de lo jurídico como un universo aparte e indaga sus problemas radicales. Pero incluso para que esa filosofia aplicada del Derecho cumpla su misión seria preciso superar la multiplicidad de problemas, logrando plantear primariamente un solo tema, del cual se deriven los demás, a saber, el tema del sentido radical de lo jurídico, pasando así de una filosofia jurídica aplicada

* Resenha que o ilustre mestre LuIS LEGAZ y LACAMBra publicou no Anuario de Filosofia del Derecho do "Instituto Nacional de Estudios Jurídicos”, Madrí, 1956, p. 437 e segs.. 
a una filosofia del Derecho como capítulo de la Metafísica, en la cual se integre lo jurídico en una concepción unitaria y totalitaria.

Aludimos a esta aspiración a unidad, porque nos parece que cuando Miguel Reale, el máximo filósofo del Derecho de Brasil en la hora presente, expone los rasgos fundamentales de una concepción "tridimensional" del Derecho, se encuentra de lleno en esta dirección. Para él, en efecto, toda conducta humana consiste en el hecho de una energia espiritual que, imantada por un valor dominante, se inclina a realizarlo como ley, como norma. Entre hecho y valor se establece una tensión que no puede resolver-se en una unidad; el mismo ser humano que es esencialmente libertad e innovación, ha de formalizarse y legalizarse, y de ahí el carácter provisional de toda norma ética cuya universalidad reside en la tensión inevitable que la libertad establece entre realidad e ideal. Por eso la experiencia ética presenta siempre una tensión y una implicación necesarias entre las circunstancias de hecho y el plano de las valoraciones, lo que se refleja en la natureza y el devenir de sus normas.

Pues bien, en el ámbito del Derecho, esta tridimensionalidad se confirma. Pero, entonces, una teoría tridimensional debe señalar precisamente la exigencia de una comprensión integral de la experiencia juridica, que tendrá que ser el resultado de la convergencia de tres grandes movimientos doctrinales, que son el normativismo jurídico (comprensión del Derecho como sistema de normas), el eticismo jurídico (subordinación rigurosa del sistema de normas a los valores morales) y el empirismo jurídico (que destaca la dimensión fáctica del Derecho). La primera intuición del orden social, dentro del cual se integra el Derecho, la primera imagen que el hombre tuvo del Derecho, fué una imagen del valor, como vivencia confusa de valores, permaneciendo inseparables la concepción del universo físico y la del mundo moral (consideración de la naturaleza como sociedad y de la ley causal como norma, puesta de relieve por Kelsen). Más tarde, el Derecho es visto como 
norma, como lex. Es el momento en que nace la Jurisprudentia. Los romanos supieron que la justicia se revela en el factum de la conducta humana, como experiencia humana: "ex facto oritur ius". El jurista ha de invocar la "ratio" de cada circunstancia para establecer su medida, su regla: la "ratio iuris" determina la "regula iuris". Por último, el Derecho es visto como hecho histórico y social. Ahora bien, el Derecho es todo eso, implicándose recíprocamente: pues la norma que el jurista estudia representa una integración de hechos según valores o, en otras palabras, es expresión de valores que se concretan en la condicionalidad de los hechos histórico-sociales.

La concepción tridimensional no pretende ser radicalmente nueva. Miguel Reale reconoce que hay muchas teorias tridimensionales: pero se trata de una tridimensionalidad abstracta y genérica, que desintegra la unidad de la concepción jurídica en diferentes aspectos o puntos de vista (sociológico, eticista, normativista). El problema está, pues, en lograr una doctrina tridimensional específica e integrante del Derecho, en la que el filósofo, el jurista y el sociólogo consideren el Derecho en la totalidad de sus elementos constitutivos - el valor, la norma y el hecho aunque cada uno vea los otros dos factores en función del que más directamente le interesa. No se trata, por consiguiente, de "armonizar" los resultados de ciencias distintas, sino de hacer un examen previo de la correlación esencial de los elementos primordiales del Derecho, recíprocamente implicados en una conexión necesaria, que también hace que se abarque en una unidad viva los problemas del fundamento, de la eficacia y de la vigencia.

Como se integran el valor, el hecho y la norma en esa unidad viva postulada por Reale? Para nosotros el Derecho es una forma de vida social, en cuanto posee íntimamente un sentido positivo o negativo de justicia y que se expresa en un sistema normativo. Es, pues, hecho, porque la vida social y sus formas son un hecho, como son un hecho las concretas valoraciones que la informan y los sistemas 
normativos en que se manifiestan: es valor, porque esas valoraciones no son sólo un hecho empírico, sino que en ellas se patentiza la exigencia de un valor o sentido de justicia sin el cual no existiría el hecho empírico del Derecho: y es, todo él, norma, porque la norma no está sólo en las manifestaciones normativas, en el sistema de legalidad, sino que radica ya en la condición del Derecho de forma de la vida social. También para Reale la norma reúne entre sí los otros dos elementos, proyectándose para el futuro como esquema de conduta posible, factor condicionante y condicionado, valor y hecho en síntesis dinámica; así es posible concebir el Derecho como momento de la vida espiritual, que se objetiva como atributividad social, hecho social al que un valor impone un significado, y valor que no se concibe desprendido del hecho al que adhiere y gracias al cual se realiza históricamente; y así también es posible penetrar en el sentido unitario y dinámico de la realidad juridica, que se presenta tridimensional en su proceso, como experiencia estimativa que es, condicionando el mundo del ser nuevas aperturas a las exigencias ideales de los valores en su objetividad atributiva.

La obra de M. Reale se promete como un Cursus completo de filosofía del Derecho. El volumen I sólo incluye la "propedéutica filosófica" (tomo I) y la "ontognoseología jurídica" (tomo II), pero faltan los volúmenes correspondientes a la espistemología, la deontología y la culturología jurídicas. La expresión "ontognoseología" revela una influencia de la metafísica del conocimiento de N. Hartmann, para el cual la ontologia del objeto del conocimiento y la ontologia del conocimiento del objeto - dos aspectos de una única actividad cognoscitiva - son las dos investigaciones a que da lugar la inserción en un mismo plano ontológico del sujeto y el objeto correlacionados. Ahora bien, lo importante es que para Reale la filosofía es ontognoseologia y lógica, teoría general de la ciencia; pero no es eso sólo, pues es también teoría de los valores, o axiología, o metafísica, teoría del ser, o conocimiento del 
universo y de la vida: de nỉngún modo puede dejar de ser una estimativa transcendental del universo y de la vida y una indagación fundamental sobre el destino y la acción del hombre, y no puede reducirse a una lógica de las ciencias o a un lenguaje técnico del saber cientifico.

En el plano ontológico en sentido estricto - teoria de los objetos - admite Reale la existencia de objetos ideales, pero niega la concepción idealista y ontológica de los mismos, propia de las últimas manifestaciones de B. Russell y de los axiologistas como N. Hartmann. En consecuencia, niega también la actitud "platonizante" de este último ante los valores. El problema del valor, a juicio de REALE, no se puede entender fuera de la historia. Los valores obligan porque representan al hombre mismo como autoconciencia espiritual; y se revelan en la historia y por la historia, porque esta es, en el fondo, el reencuentro del espiritu consigo mismo, del espiritu que se realiza en las experiencias de las generaciones, en las vicisitudes de lo que llamamos "ciclos culturales" Entonces los valores tienen objetividad, pero objetividad relativa, esto es, referida a un sujeto universal de estimativa, que es el hombre, la persona humana. El hombre es el valor fundamental, algo que vale por sí mismo, cuyo ser es su deber ser: no simple entidad psicofísica o biológica, sino una posibilidad de innovación y de superación. El hombre tiene conciencia de su dignidad y de esa autoconciencia nace la idea de persona, según la cual no se es hombre por el mero hecho de existir, sino por el significado o sentido de la existencia. Cuando apreciamos el problema del hombre, toda ontologia se resuelve en axiologia y se abren las perspectivas de la metafísica. En verdad, sólo del hombre sabemos que es y al mismo tiempo debe ser, pero se comprende que la misma cuestión puede plantearse con relación a la totalidad de los seres, que lleva a la inevitable especulación sobre el sentido de ser en general.

Pero el problema del valor conduce al problema de la cultura. El espiritu humano se proyecta fuera de sí, mo- 
delando la naturaleza a su imagen. El caudal de bienes objetivados por el espíritu humano en la realización de sus fines específicos, eso es la cultura. La experiencia jurídica es una forma de experiencia cultural que antecede a la respectiva conciencia científica. La ciencia jurídica aparece como una interpretación lógico-formal y normativa de una sociedad que hasta entonces vivió el Derecho sin teorizar-lo. Pues el hombre no es sólo un realizador de intereses, de cosas valiosas o de bienes, sino también un ser que siente la indeclinable necesidad de proteger lo que crea, de tutelar las cosas realizadas y de garantizar para sí mismo, por encima de todo, la posibilidad de crear libremente cosas nuevas. El Derecho marca y refleja esas tendencias o inclinaciones fundamentales del espíritu, en la tutela y realización de valores, por lo cual la historia jurídica revela siempre una tensión intima entre el movimiento hacia el futuro (amor de nuevos bienes) y la estabilidad y la tradición (amor de bienes adquiridos). Esta concepción abre perspectivas renovadoras para la ciencia jurídica, porque nos da conciencia de que el Derecho no es un presente, una dádiva que el hombre haya recibido en determinado momento de la historia, sino el fruto maduro de su experiencia multimilenaria, revelándose como fenómeno universal esencialmente ligado a la actividad perenne del espíritu.

La concepción culturalista del Derecho propugnada por Miguel Reale se afirma como una concepción humanista. La persona himana es el valor fuente de todos los valores. Por eso, cuando el hombre estudia la cultura, no hace sino estudiarse a si mismo, en la riqueza imprevisible de sus energias creadoras, como si el espiritu se reencontrase o se reconociese ref́lejảndose en İos h̉echos de la historia, la objetividad de los mismos implica un deber, porque estamos obedeciendo a nosotros mismos, en nuestro significado universal de hombres. La persona es la constante axiológica del valor de lo justo. Y lo justo, la justicia, es el valor fundante del Derecho, entendiendo lo justo no como simple relación extrírseca o formal, aritmética o geométrica, sino 
como el contenido de las relaciones, en cuanto representan un bien intersubjetivo, que es el bien común. Hay, pues, un bien individual y un bien social, objeto de la moral y del Derecho, respectivamente, formas - advierte REALE que nos agotan la realidad de la Etica, pues hay otras formas de comportamiento (las reglas de la costumbre, los convencionalismos sociales) que realizan a su modo el valor del bien sin reducirse a aquellas dos formas fundamentales. El bien individual $y$ el bien social son distintos, pero no pueden separarse radicalmente, del mismo modo que la concepción "personalista" del Derecho no puede caer en un individualismo. El individuo debe ceder ante el todo, pero mientras no se afecte a su valor de persona, o sea, a su plenitud de hombre en cuanto hombre. La arbitrariedad consiste en sobrepasar la esfera de la personalidad. El personalismo es entendimiento de personas, no de individuos. Ese es el sentido de la alteridad, como nota esencial de lo jurídico, que Miguel Reale defiende ampliamente. Su característica es ser una "bilateralidad atributiva", que representa un nexo objetivo que pone en relación dos o más sujetos, discriminándoles esferas autónomas de ser y de obrar y atribuyéndoles pretensiones, que pueden ser reciprocas o no, pero que siempre se hallan provistas de garantía dimanada de la objetividad del enlace. Es, pues, el Derecho, la vinculación bilateral-atributiva de la conducta humana, para la realización ordenada de los valores de convivencia: una condicionalidad no lógico-transcendental (como en KANT) ni sociológica (como en JHERING), sino histórico-axiológica de la existencia de un orden social justo, en el que los hombres y los grupos puedan desenvolverse libremente, así como completarse económica y éticamente unos a otros en el sentido de una comunidad concreta. A diferencia de la Moral, de la Estética, etc., el Derecho no tiene por fin un valor especifico que determine por sí solo la acción humana, sin implicar la vigencia consecuente de otros valores. El artista vive en razón de la belleza, como la moral se endereza plena y exclusivamente a la plenitud 
del ser personal. Pero el Derecho no tiene como destino realizar la justicia entre sí y por sí, sino como condición de la realización ordenada de los demás valores. De ese modo, el Derecho es la condición primera de toda la cultura, y en eso precisamente reside la dignidad de la Jurisprudencia.

Tales son las lineas fundamentales de este primer volumen de la filosofía jurídica de Miguel Reale, en la que destaca un claro seńtido de modernidad. Resuenan en su pensamiento los ecos de toda la mejor filosofía actual, fundidos en una síntesis armoniosa que no se diluye en un incoloro sincretismo. Le falta, sin embargo, una referencia a los problemas absolutamente últimos y fundamentales; no queda en claro si su humanismo culturalista y jurídico, que compartimos, es un humanismo antropocéntrico o un humavismo teonómico; hubiera sido menester, en consecuencia, una teoría total de la persona humana. Quizá, por eso, en algunos puntos no se da una precisión que hubiera sido deseable, como ocurre con el problema del Derecho natural, que el autor declara aceptar "con cautelas y reservas", y la verdad es que este fundamental problema de la ontologia y la axiología jurídicas no ha sido objeto de consideración temática por parte de Miguel Reale.

Por lo demás, su libro está lleno de incitaciones valiosas y sugerentes y la claridad de la exposición y la rica utilización de la bibliográfica jusfilosófica clásica y moderna hacen de él no sólo un útil instrumento de trabajo en el plano didáctico, sino una obra positivamente estimable en el ámbito de la actual filosofía del Derecho. 